\title{
Studies on urban mobility and use of ICT in relation to cities' sustainability. A bibliometric analysis
}

\author{
ANA ESCOBAR ${ }^{\mathrm{a}}$, JHON ZARTHA ${ }^{\mathrm{b}}$, LUCIANO GALLÓN ${ }^{\mathrm{c}}$ \\ a. Sustainability Specialist, Tigo Colombia, Cra. 16 \#11a Sur100, Medellin, Postcode 050022, Colombia \\ b. Professor, Universidad Pontificia Bolivariana, Cq. 1 \#70-01, Medellin, Postcode 050031, Colombia \\ c. Professor, Universidad Pontificia Bolivariana, Cq. 1 \#70-01, Medellin, Postcode 050031, Colombia
}

KEYWORDS: Urban mobility; Urban traffic; Information Technologies; Smart Cities; Sustainable Development

ABSTRACT: The objective of this article is to present three groups of analysis in urban mobility studies, their relationship with the use of ICT and how the findings promote urban sustainability. 40 documents in the
Scopus database were systematically reviewed. The research methodology used was mixed, where methods of qualitative analysis and bibliometric analysis were combined with the Vantage Point software. The results made it possible to establish which projects are at the forefront of the study of urban mobility. This article will contribute to future research and could be useful for discussions on public policy on urban mobility.

\section{INTRODUCTION}

With the demographic explosion experienced in the 20th century and, with it, the densification of urban space, the sustainability of cities has increasingly become an urgent issue. The projections of the (United Nations, 2017) for 2050 confirm the population growth trend of the last fifty years: the planet will experience the demand of some 9.8 billion people, according to (Leone et al., 2017), and about $70 \%$ will be concentrated in cities (López Bernal, 2004).

Urban expansion and extensive construction in cities' peripheries consume valuable resources of the planet such as land and water. This generates economic costs in terms of infrastructure and energy, social costs such as congestion of transport networks, and increases segregation and specialisation of land use and environmental costs such as the degradation of the environment. All this wards the city off from the model of sustainable development and undermines certain traditional characteristics, such as its compactness and diversity (Camagni, Gibelli, \& Rigamonti, 2002).

In accordance with the eleventh Sustainable Development Goal (SDG), Sustainable cities and communities, by 2030 it is necessary to make cities and human settlements inclusive, safe, resilient, and sustainable. The sustainability of cities encompasses various topics, including urban transport. The issue of mobility of cities is an important factor that not only generates discussions about urban infrastructure, but also the industrial activities of a city, the habits of its citizens, ways of life, the administrative management of the city, the state of air quality, environmental pollution, urban growth, the logic of urbanisation, among many other elements (United Nations, 2015).

Intelligent mobility is a global trend that has been developing since the 1990s (Lopez-Carreiro \& Monzon, 2018) with the aim of making processes more efficient within a specific urban space. The intelligent management of cities depends not only on the evolution of Information and Communications Technology (ICT) and the interconnection of their services on digital platforms, but on the integration of the urban system, paying attention to the areas of sustainability (economy, environment, and society) without losing sight of the political and cultural contexts. Academic studies have been devoted to understanding this situation and it is the interest of this investigation to present the trends in sustainable urban mobility ${ }^{1}$.

This article is divided into five sections: The first one presents a review of concepts related to the paradigms of sustainability and urban mobility, as well as the evolution of the latter towards intelligent and sustainable systems. The second part describes the methodology carried out through four stages. The results obtained are presented in the third section. In the fourth, the discussion of the results is presented based on three axes of analysis. The document ends with the presentation of conclusions for future studies on sustainable urban mobility.

\subsection{Theoretical framework}

\subsubsection{Sustainability and urban mobility}

Faced with the excessive and indiscriminate consumption of energy, materials and natural resources, the approaches of sustainable cities are seen as a utopia for critics of urban models who consider that the acceleration of the global ecological decline is due to their perpetuation over time. Cities are seen as the most complex socio-ecological system developed by human beings, which suffer constant states of vulnerability due to unpredictable factors that disturb them and end up generating significant social, economic, cultural and environmental costs (Zhang \& Li, 2018)there is a large overlap between the meaning of resilience and sustainability, which threatens to weaken both concepts. In this study, we discuss the difference between urban resilience (UR.

It is necessary to understand how urban systems can be maintained over time and evolve without losing the elements

1 For the research goals, we decided to use the term "urban mobility" instead of "urban transport" because it is a more comprehensive term where other types of mobility enter the city that include different levels of mobility. This is the case of mobility on foot or of pedestrians in the public space of the city. Therefore, the design of the information search equations was based on urban mobility. 
that define it. Sustainability is understood as the capacity of a system to perpetuate itself during a certain period in specific physical conditions that, however, change with time according to its evolutionary dynamics. Sustainability over time is an expected characteristic to preserve life or maintain initial ecological conditions that enable the well-being of future generations (Daly, 1990).

Sustainability of urban conglomerates is related to 'active process of synergetic integration and co-evolution between the subsystems making up a city without compromising the possibilities for development of surrounding areas and contributing by this means towards reducing the harmful effects of development on the biosphere'(Zhang \& Li, 2018) there is a large overlap between the meaning of resilience and sustainability, which threatens to weaken both concepts. In this study, we discuss the difference between urban resilience (UR. This implies having the ability of the urban system to decide to grow in its physical and material structure as it seeks to make this growth a tool for the achievement of its social, economic and environmental objectives (López Bernal, 2004).

With the growth of economy, the increasingly high concentration of human activities and the intensification of population density in urban centres, urban mobility has been characterised as one of the priority issues to be resolved in modern cities. The study of this phenomenon in cities begins to be conceived in a broader and integrated way with urban life forms, considering it essential to speak of urban mobility more than means of transport. The individuals of a city are not only responsible for interacting passively and mechanically with the modes of transport available and moving from one place to another without any consideration, but rather they respond in a viable way with their movement interacting with everything else that is around them (Jensen, 2013).

This change in the vision of movement in a city allows us to understand it better through its configuration as a network of roads where it is essential to talk about the dynamics of access and use of space, in such a way that it is possible to move within it to receive and transmit information (Jensen, 2013). Urban mobility can be understood as the set of movement flows within the city (Fistola, Raimondo, \& Rocca, 2017) configured of people, goods, information and signs that circulate in networks of relationships (Jensen, 2013).

Therefore, urban mobility is the ability of individuals to move from one place to another (Costa, Morais, \& Bertolde, 2017) having the possibility of doing so in an organised and coherent manner according to their physiological, intellectual and socio-economic needs, and using existing transport, public services and ICT infrastructure (Vidovic, Mandzuka, \& Brcic, 2017).

\subsubsection{Urban mobility: smart models}

Due to the increase in the growth of urban centres, the high demand for public and private transport fleets, as well as a spontaneous emergence of transport systems, a large number of cities in the world experience deteriorated mobility that has led to important socio-environmental problems (Costa et al., 2017). Given the changes that are occurring in the use of transport, in its demand and in the way of travelling around the world, the study of mobility and innovation in sustainable systems becomes a pressing action. The factors that determine these changes are diverse: socioeconomic (lifestyles, suburbanisation, increasing use of ICT, etc.), technical (development of new means of transport such as e-cars and e-bikes, intelligent transport systems, etc.), economic (energy and transport prices) and political (Aguiléra \& Grébert, 2014).
The concept of sustainable urban mobility implies thinking about the structural means, as well as the daily life of the citizens, their cultural structures, and the actions they carry out regularly. Sustainable urban mobility involves integrating layers of analysis that allow us to see the multidimensionality of urban transport from socio-economic and spatial aspects such as age, gender, working conditions, the type of physical conditions of citizens, types of intermodal transport, travel expectations, routines and social habits, as well as the type of situations that represent problems of accessibility and mobility for some users (Costa et al., 2017; Mataix, 2010).

Thus, sustainable urban mobility is the ability of cities to meet the needs of society to move freely, have open access to places in the city, be able to communicate, negotiate in urban spaces and interact with others without sacrificing other conditions of daily life. So, this concept implies the development of actions that contemplate the reduction of displacements and their replacement by means of technological solutions, as well as political measures that address the decrease of the private automobile, the articulation of intermodal transport, the use of land and the increase of social innovation (Costa et al., 2017).

Sustainable urban mobility is also related to technological advances and the incursion of ICT in the generation of solutions for the city. Growth of urban pressure generates, in turn, pressure on urban transport systems and, therefore, the demands for new solutions in mobility services increase, especially in the mixture of the traditional public service with new modalities that are achieving the replacement of the private automobile (Kamargianni, Li, Matyas, \& Schäfer, 2016). In the last twenty years, travel information systems went from presenting independent solutions to developing integrated information systems. Now, Advanced Traveller Information Systems (ATIS), use ICT to present travel information to users of various modes of transport, assist in reservation processes, planning and use of intermodal services (Himmel, Zaunbrecher, Ziefle, \& Beutel, 2016).

Specifically, the use of the Internet has brought about changes in urban mobility. Developments in ICT have generated transformations in the demand for transport services and have opened several opportunities with the incursion of certain tools and services. This is how ICTs have influenced the means of transport, infrastructure, routes and, in general, the behaviour of its users (Snellen \& de Hollander, 2017)there are tensions between short and long term interests, public and private interests and between efficiency and equity. Analysing how new developments impact public values that are considered relevant in the transport debate shows that there is a wide range of aspects to consider. We discuss four public values. Accessibility is concerned with providing access for all, making sure there are transport options available as well as taking care that people have the capabilities to access them. Affordability or (cost.

\section{MATERIALS AND METHODS}

With the purpose of conducting a literature review in sustainable urban mobility and its integration with ICTs, the following stages were followed:

Stage 1: The sources of information were identified from the Scopus database using these keywords: Urban Mobility, ICT and Sustainability.

Stage 2: The search criteria were selected and focused on the years 2014-2018. Due to the few data found by an equation with three keywords, the word Sustainability was eliminated from the search and a more comprehensive one was determined, leaving only ICT and Urban Mobility. The final search 
equation was: TITLE-ABS-KEY (Urban mobility) AND ict AND (LIMIT-TO (PUBYEAR, 2018) OR LIMIT-TO (PUBYEAR, 2017) OR LIMIT-TO (PUBYEAR, 2016) OR LIMIT -TO (PUBYEAR, 2015) OR LIMIT-TO (PUBYEAR, 2014) OR LIMIT-TO (PUBYEAR, 2013)) AND (EXCLUDE (PUBYEAR, 2013)) AND (LIMITTO (DOCTYPE, cP) OR LIMIT- TO (DOCTYPE, ar)). With this equation it was possible to verify that the documents present in the equation with the three keywords were included in the equation finally defined.

Stage 3: Based on the search equation, 62 documents were retrieved. All were chosen for their summaries to be read. However, only the results of the scientific articles published in journals were considered. Finally, 40 documents related to the use of ICT and sustainable urban mobility were analysed. Five articles were excluded from the initial list of articles because they were not available in the academic databases or on the Internet. The excluded documents were: (Passalacqua, 2014; Kahlen, Lee, Ketter, \& Gupta, 2018; Rehm, Faber, \& Goel, 2018; Alam, Fernandes, Almeida, Ferreira, \& Fonseca, 2017; N. Li, Chan, Hsu, Fu, \& Mao, 2017)yet are responsible for up to eighty percent of global greenhouse gas emissions and seventy-five percent of natural resource consumption. They impact air and water quality, alter resource consumption patterns, and pose unique challenges for the environment, energy, and infrastructure. Addressing these challenges requires understanding the city as the nexus of environmental context, built infrastructure, and human communities, which can only be achieved by close collaboration among educated professionals from a wide range of related domains. This paper describes the experiences of a university course that was developed to prepare students from diverse academic backgrounds to understand the nature of and learn the required skills to address sustainable urbanization challenges. The course, which was partially online enabled by the latest information and communications technology (ICT. For the process of analysing the documents, an Excel file was created that contained the following criteria: Name of the article, Author, Year, Country, Journal, Journal SJR, Quartil de Scimago, CiteScore 2016, SNIP 2016, Type of publication, Abstract, Keywords and University of Affiliation.

Stage 4: To generate the analysis, two types of matrices were built in Excel: 1) a global matrix that included the categories year, countries, name of the article, authors, summary, keywords, and affiliation. This was processed by the software VantagePoint 10.0 to analyse the academic tendencies in a descriptive way that arose from the results of the literary revision. The list was cleaned for both keywords and key phrases. 2) A detailed matrix with year fields, document name, authors, problem, objective, theoretical framework, study proposal, gaps, research methodology, summary, country, and conclusions related to analysis.

\section{RESULTS}

The following results were found from the analysis of the 40 documents that are directly related to sustainable urban mobility and the use of ICT. These results are presented in two parts: 1) articles published by year and country, and 2) the keywords, key phrases and its appearance in the years consulted.

\subsection{Articles published by year and country}

Five articles were published in 2014, six in 2015, nine in 2016, 17 in 2017 and three in 2018. This shows that there has been an exponential growth that, according to the trend, could be achieved for the following years. Italy is for the sample of this study the country that has generated the most publications in the last five years. With a representa- tiveness of $28 \%$ of the publications, Italy generated publications throughout all the years analysed. Then there are countries in the European region: Germany, Portugal, the United Kingdom, France, Spain, Greece, the Netherlands, and Poland, which indicates that the advances in terms of sustainable urban mobility are concentrated in this region. However, there is a presence of countries in the North American region such as the United States, and South America with Brazil and Mexico.

Figure 1 reveals the relationships between years and countries. Italy is the only country that, in addition to having the largest number of publications, is distributed over the five years selected. As can be seen, seven countries in the European region developed publications in the year 2017.

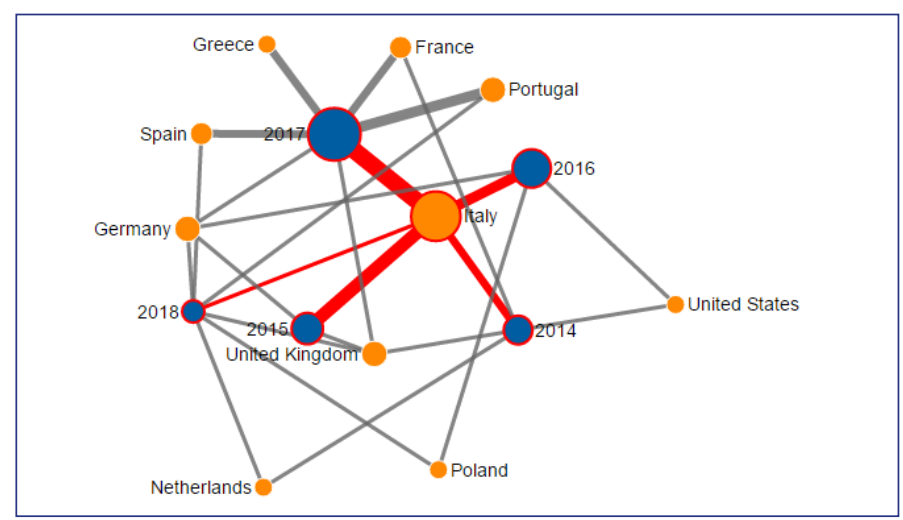

Figure 1. Top 10 countries by year relation. Own elaboration.

\subsection{Analysis according to keywords and phrases}

For the analysis of urban mobility integrated to the use of ICT, it was necessary to observe the emergence of keywords and key phrases according to their representativeness in each of the articles. Figure 2 and Figure 3 reflect three essential situations:

1. The terms used in the search equation (Urban Mobility and ICT) are predominantly present.

2. The concept of sustainability emerges in a visible way in several phrases and keywords such as Sustainable Urban Mobility and Sustainable Cities, which condense the variety of appearances in the articles analysed.

3. Concepts such as Smart City, Urban Mobility Simulation, Intelligent Transport Systems, Smart Urban Mobility, Collective Actions, Cooperative Intelligent Transport Systems, Socio-technical Systems, Systems Approach, and Innovation arise as a correlate of the key concepts of this study.

The discussion on the academic trends in the study of urban mobility for the sample of selected articles is related to ICT, sustainability of cities, models and sustenance of smart cities, presentation of analysis systems, collective and participatory actions, as well as innovation processes.

According to the years, it can be seen in Figure 4 how the keywords used in the search equation, both Urban Mobility and ICT, appear with greater force as the articles are more recent. Emerging words such as Sustainable Urban Mobility and all those related to intelligent systems (Simulation, Smart City, and Intelligent Transport Systems) have been maintained over the years, demonstrating the consolidation of these approaches in the studies and in the academic literature. Furthermore, in Figure 5 it is possible to see the relationship of the most influential authors with the key themes of this research where ICT, urban mobility, ITS, smart city and Emobility are relevant to them. 


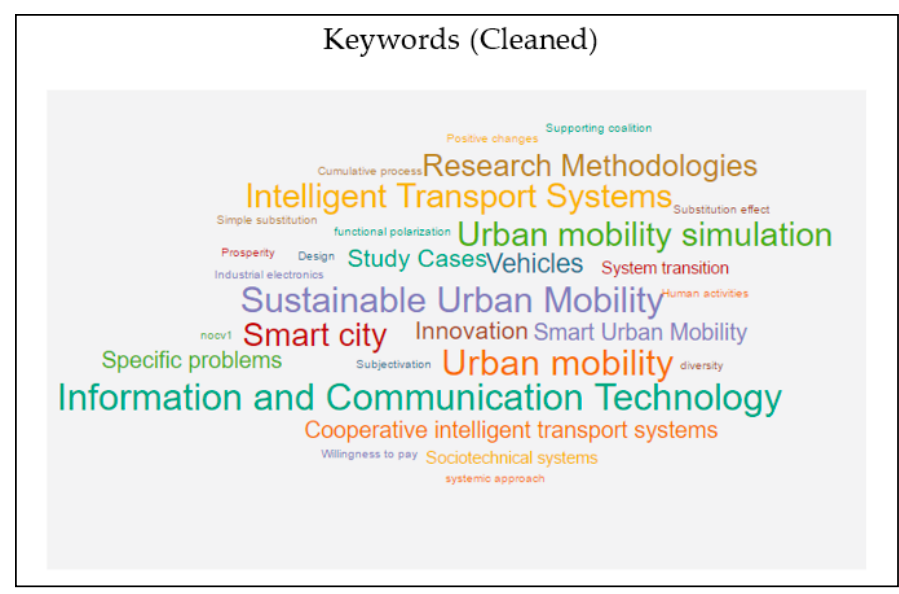

Figure 2. Cloud of keywords. Own elaboration.

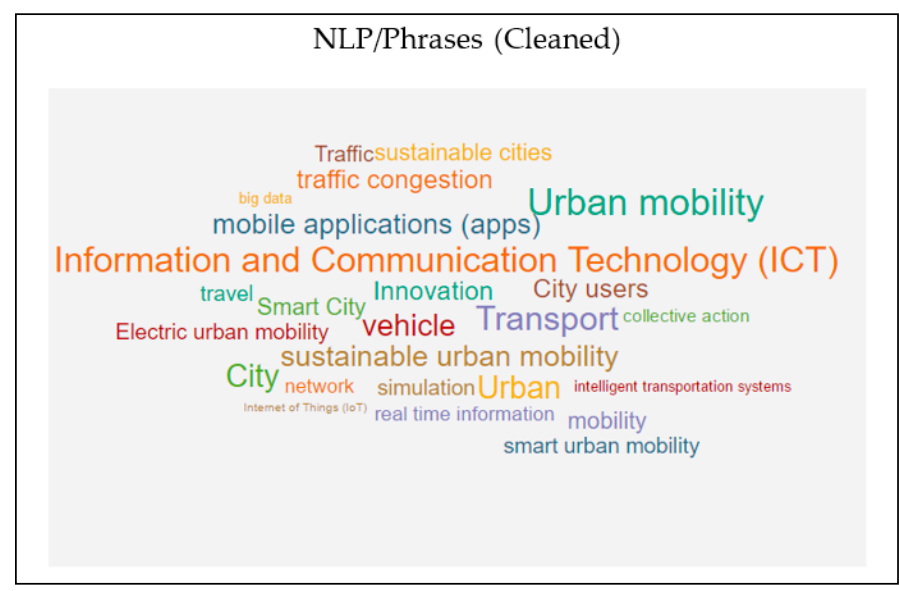

Figure 3. Cloud of key phrases. Own elaboration.

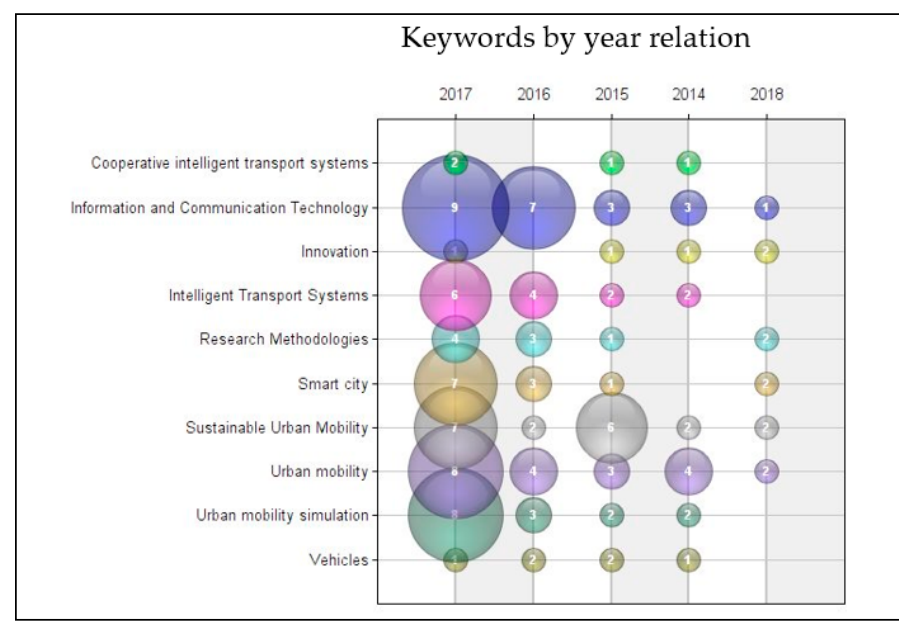

Figure 4. Top 10 keywords by year relation. Own elaboration

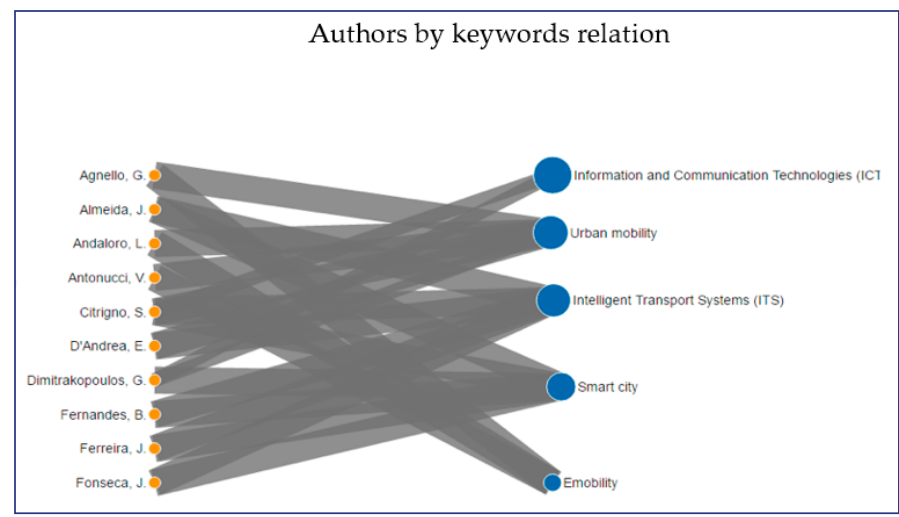

Figure 5. Top 10 authors by keywords relation. Own elaboration

\section{DISCUSSION}

Urban sustainability and smart cities models are cross-sectional concepts that appear in the studies on urban mobility and ICT use within the last five years. The discussion on the integration of new digital technologies as fundamental tools in the construction of sustainable societies opens a field for theoretical enquiry on how to move towards holistic proposals in which both technological solutions and models are present and where communication and participation with citizens is strengthened. Although there is no single definition of sustainable and intelligent cities, the academic trends mentioned below help to understand precisely the transitions required to grasp mobility needs for cities.

After the analysis based on the authors, the years, the countries, the keywords, and phrases in the articles through the Vantage Point tool, and the qualitative analysis of the 40 selected documents, three axes of discussion were chosen that focus on the articles and the type of analysis developed: 1) modelling and simulation of vehicular traffic, 2) incursion of digital technologies in urban mobility, 3) intelligent and sustainable urban mobility systems.

\subsection{Modelling and simulation of vehicular traffic}

A total of seven articles were published between 2014 and 2017 that are characterised by generating solutions for urban mobility problems through the construction of algorithms and mathematical models that propose to articulate the systems of traffic in an intelligent way. That is, through simulations and modelling of situations with data from mobile telephone users (D'Andrea \& Marcelloni, 2017; Shields, Doody, \& Scully, 2017)GPS traces are pre-processed and placed in the road map. Then, the system assigns to each road segment of the map a traffic state based on the speeds of the vehicles. Finally, it sends to the users traffic alerts based on a spatiotemporal analysis of the classified segments. Each traffic alert contains the affected area, a traffic state (e.g., incident, slowed traffic, blocked traffic, data from interconnected vehicles and GPS (Cárdenas-Benítez et al., 2016), real-time monitoring sensors (Rakkesh, Weerasinghe, \& Ranasinghe, 2016), historical data on congestion and road situations in the city (Elhatri, Tahifa, \& Boumhidi, 2017) and traffic congestion metrics (Batur \& Koç, 2017)it is vital to achieve and maintain social behavioral change for shifting our modes of mobility from inefficient, wasteful and motorized means to cleaner, greener, healthier and more economic means such as walking, cycling and public transportation in addition to smart use of land, intelligent transportation systems, and clean and green vehicles. This study is based on a critical review of literature in order to establish a framework of social behavioral change policies, particularly developed and tested for urban mobility and traffic congestion. First, various mega cities were compared on different sustainability indicators to better understand the case of Istanbul. Then, selected policy potentials, namely Travel Demand Management (TDM.

Urban mobility studies show, how trends towards the development of solutions to the problems of traffic and congestion in the city have been evolving in accordance with the dynamics of smart cities. Preliminary studies in the literature reviewed conceive urban mobility as the movement of vehicular traffic in cities (Geroliminis \& Daganzo, 2008) where it is necessary to contemplate relationships between vehicle flow and density (Daganzo, Gayah, \& Gonzales, 2011), and interactions between physical conditions and human activities (F. Z. Li, Fisher, Brownson, \& Bosworth, 2005). The objective is to predict the speed of vehicles and the distribution of traffic in the road network according to supply and demand and routes of origin-destination (Daganzo, 2007) moving from 
approximate models to reality, especially in times of heavy traffic and congestion where the system is dynamic.

The foundation of this analysis focuses on the understanding of how, where and when people move daily, especially in densely populated areas, so that they can propose solutions in the design of transport infrastructure and make its use more efficient. This academic trend presents an interest in the configuration of Intelligent Transport Systems (ITS) to address and alleviate transportation problems and congestion. In general, one ITS is based on location-based information: it monitors and processes the location of a certain number of vehicles used as probes to obtain information on estimated travel time, driving conditions and traffic incidents. In its most recent form, this is done through the monitoring of telecommunications networks and the data they obtain from mobile phone users (Calabrese, Colonna, Lovisolo, Parata, \& Ratti, 2011; D'Andrea \& Marcelloni, 2017; Steenbruggen, Tranos, \& Nijkamp, 2015; Zheng, Rajasegarar, \& Leckie, 2015), construction of a Traffic Management System based on social networks and the potential use of smart cars that allow detection and faster and more accurate traffic congestion mitigation (Djahel, Doolan, Muntean, \& Murphy, 2015).

\subsection{Incursion of ICT in urban mobility}

Some studies provide frameworks of analysis for ICT use in urban mobility and the potential development of new conceptualisation and 16 publications evidence the incursion of ICT in urban mobility. Of these, six lines of analysis were found: 1) Effects of urban mobility, 2) Impact of ICT on urban mobility, 3) Diagnosis of urban transport and its trends in the future, 4) Systemic analysis with emphasis in socio-technical systems, 5) Conceptual proposals for the understanding of urban mobility, and 6) Design of indicators to measure sustainable urban mobility.

\subsubsection{Effects of urban mobility}

Kozievitch et al. present an investigation based on a data analysis of Geographic Information Systems (GIS) that characterises urban noise produced by transport systems. Limitations on the study's use of data from sensors in terms that ignore the motivations of people moving around the city raises the need for various sources of information data to give a more precise graphic sense to the characterisation of the phenomenon of urban noise. With the help of tools to generate data integration, the analysis generated helps to explore how it is possible to obtain a geo profile to make decisions according to the dynamics of specific spaces of the city, land use and decide on the type of future uses according to the problematic situations regarding mobility in the city (Kozievitch, Gomes, Gadda, Fonseca, \& Akbar, 2016).

\subsubsection{Impact of ICT on urban mobility}

The analysis of the impacts of ICT on urban mobility generates an academic trend with six articles that ask how the incursion and integration of ICT in urban mobility generates positive changes. Broadly speaking there is a consensus among the studies on the benefits and potentialities of ICT in the generation of solutions for urban mobility.

Cohen-Blankshtain \& Rotem-Mindali indicate three dimensions in their study on which ICT have an effect on sustainable urban mobility: 1) ICT have the potential to affect travel demand directly, 2) ICTs also have the potential to change the transport system by introducing new technologies into existing transport technologies and 3) ICT can directly affect urban forms (land use, demand for certain types of land use and accessibility to certain places) (Cohen-Blankshtain \& RotemMindali, 2016). Pronello et al. study how public and private transport users may have a willingness to pay for an Advanced Traveller Information System (ATIS). They understood that although the integration of ICT in the urban mobility system can generate positive impacts, the change in behaviours of travellers' behaviour does not depend solely on these initiatives. So, new technologies alone are not powerful enough to change the behaviour of travellers. Authorities must also carry out co-ordinated actions to improve transport networks where alternatives exist for the use of cars and introduce policies to reduce their usage (Pronello, Duboz, \& Rappazzo, 2017).

Tafidis et al. concluded that ICT interventions in transport networks can be beneficial in terms of $\mathrm{CO} 2$ emissions and cost reductions, and may therefore become an important tool for local authorities and policymakers (Tafidis et al., 2017). Serna et al. address the way in which information from social networks and User-Generated Content (UGC) can be used to analyse urban mobility. This study identifies how the information collected in social networks can complement, enrich (or even replace) the data traditionally obtained from origin-destination surveys (Serna, Gerrikagoitia, Bernabé, $\&$ Ruiz, 2017)in fact one of the challenges posed by booming urban populations is the question of mobility. Traditional travel survey methods used to study urban mobility are very expensive, and the data collected are of poor quality. This is mainly explained because of the difficulty of getting a representative sample of the population, and the lack of motivated participants. Therefore, travel surveys are carried out less and less frequently, and the result is that good travel data is not available to develop mobility and travel behaviour studies. Information and Communication Technologies (ICT.

The convergence of ICT with electric mobility solutions is essential to generate an experience that satisfies its users and really changes the behaviour of citizens. In their analysis of electric bicycles aimed at high school students, Arsenio et al. highlight how users preferred an electric bicycle integrated with ICT systems such as: sensors for their safety and protection, a GPS to see the shortest routes, bicycle to bicycle connections, an application to see the number of calories burned and a cooperative system of electric bicycles (Arsenio, Dias, Lopes, \& Pereira, 2017)further research is needed to understand users' preferences and the range of factors that can contribute for people to shift from car use to low carbon vehicles such as e-bikes. This paper is built on the Be4Schools $\mathrm{R} \& \mathrm{D}$ project implemented in the city of Águeda which is considered the first smart city in Portugal. It comprised the former study in the country that examined the willingness of students (aged 15-21 years.

Tyfield \& Zuev explain how China has been implementing policies so that its citizens prefer electric mobility. The authors demonstrate how the transition from conventional mobility to electric mobility in this country has not been successful because it requires not only changes in the automobile industry, but also the construction of an ecosystem that presents socio-technical transformations, fundamental techniques and their coordination with public policies, cultural areas, and advances in the digital industry. They emphasise the creation of ecosystems for the realisation of this transition where the incursion of ICT and the advances that Google and other companies in the digital industry have been developing in terms of autonomous and connected vehicles have a greater impact than advances made by traditional companies in the automotive industry where there is not necessarily a convergence of digital media and tools in electric vehicles (Tyfield \& Zuev, 2018).

\subsubsection{Diagnosis of urban transport and its trends in the future}

In the literature review several case studies diagnose the state of urban mobility in some cities, mainly European. Two such studies diagnose and evidence urban transport trends worldwide. 
Arimah presents a study that identifies how African cities have a deteriorated road infrastructure and poor public transport services. but present advanced conditions for telecommunications services, especially mobile telephone systems. However, there is no integration between the two types of services. The solutions proposed tend to the implementation of Bus Rapid Transit (BRT) services and railways that can promote more inclusion in transport and dignify mobility within cities (Arimah, 2017). Aguiléra \& Grébert suggest that between mass transportation and private car use a wide range of solutions exist that can be implemented through innovations and basic criteria of sustainable urban mobility (Aguiléra \& Grébert, 2014).

\subsubsection{Systematic analysis with emphasis on socio-technical systems}

Three studies emphasise an understanding of the city and urban mobility from the theory of systems and Socio-Technical innovation (ST) wherein the mobility of cities appears as an interdependent and interrelated element alongside other urban activities, exerting different connecting functions on the urban space.

Marletto approaches urban mobility based on the study of the theory of dynamic and complex systems, achieving a systemic representation based on a socio-technical map of relationships. He proposes an analysis of the current scenario and three projections of scenarios to 2030:1) Auto-city, 2) Ecocity and 3) Electricity, based on three variables 1) business models, 2) propulsion of technologies and 3) power. ST innovation approaches are used to show how the future of urban mobility will depend on competition between coalitions of innovative actors who support alternative transport systems (Marletto, 2014).

Kourtit et al. propose the urban plaza as an analytical framework that integrates the urban space. Making use of a systemic vision, the plaza would interconnect four fundamental pillars: 1) economy and innovation (economic capital and creative entrepreneur); 2) mobility (infrastructure, logistics, connectivity, and communication capital); 3) society (social and cultural capital); and 4) ecology (environmental capital). A sustainable urban mobility is seen here as a mobility that ensures an intelligent interconnection capable of generating city networks and providing communication and information exchange. This study assumes that the incursion of ICT does not necessarily change the mobility of cities, but it does allow for the generation of changes in behaviour patterns, in the travel experience itself and in the perception of their costs (Kourtit, Nijkamp, Franklin, \& Rodríguez-Pose, 2014).

Fistola et al. conceive mobility in an integrated way; ICT appear as an element that is part of the urban system not only as a complement but as an adopted element of the city. The systemic approach to the city allows us to visualise the existence of three urban subsystems with which the activities of mobility interact and all the other functions in the same space that is the city: 1) the physical subsystem (material component); 2) the functional subsystem (intangible component); 3) the socio-anthropic subsystem (people who live inside the city) (Fistola et al., 2017).

\subsubsection{Conceptual proposals for the understanding of urban mobility}

Schwanen explains how applications can contribute to a transition towards the sustainability of urban mobility if they are less understood as instruments for carrying out certain actions, and they come to be perceived as complete objects that exceed the relationships of which they are a part. This study presents a conceptual framework that helps to understand the relationships between mobile phone applications and physical mobility. The framework emphasises the analysis of human behaviour and social practices related to mobile phone use (Schwanen, 2015).

\subsubsection{Design of indicators to measure sustainable urban mobility}

Three of the articles that enter this trend have advanced in the construction of indicators to measure sustainable urban mobility and understand how the paradigm of smart and sustainable cities impacts on the development of viable and efficient solutions.

Lopez-Carreiro \& Monzon advance in the measurement of sustainable urban mobility by introducing the concept of Intelligent Mobility within this first larger concept, thus achieving conceptual consensus. Their study explores the current indicators to measure the intelligence of the systems in a city, which considers the need to address the dimensions of sustainability and the index of technological innovation, reaching a synthetic indicator of intelligent urban mobility that serves to understand the dimensions and areas that are stronger or weaker in the evolution of systems in the city (Lopez-Carreiro \& Monzon, 2018). Vidovic et al. delve into the construction of urban mobility indicators through the use of information obtained by the behaviour of ICT services users. It is a study that helps to understand various types of indicators as well as sources to measure mobility in a city (Vidovic et al., 2017). Battarra et al. present 12 indicators to measure the effect of ICT on urban mobility and 16 more to measure accessibility and sustainability, reaching a total of 28 indicators. This study makes a special call regarding the data that are necessary to start measuring the efficiency and results of ICT on urban mobility. Their results found that while a city is not equipped and articulated in an integral way with intelligent mobility and transport systems, the use of ICT tends not to have a positive effect on urban mobility. The more obsolete urban mobility systems are, the more difficult it is to generate real effects through the use of smart applications and systems (Battarra, Zucaro, \& Tremiterra, 2017).

\subsection{Design of intelligent and sustainable urban mobility systems}

The last of the analysis realized in the literature review is related to the design of proposals and systems to optimise urban mobility. This point collects more than half of the articles that entered the search equation, which is why it is quite significant for the discussion of this article. Other articles focused on proposing analytical and comprehensive schemes on urban mobility have already been analysed. As well as constructing information architectures that work from the modelling of data, this latter analysis provides specific solutions including the integration of ICT in urban mobility. Within this analysis four subdivisions were found: 1) Electric vehicle platforms, 2) Co-operative platforms for smart mobility, 3) Platforms for urban mobility.

\subsubsection{Electric vehicle platforms}

The studies reviewed show an important convergence between the development of electric vehicles and the incursion of intelligent technologies. Arena et al. observe the needs of users and their profiles to generate a proposal for shared electric vehicles in Italy that allows specific configurations and a user-centred performance. The centre of the proposal is Green Move, a project that allows consistent routes for the needs of users and their profiles, so that they have a customisable service (Arena et al., 2015). The proposal of Mingrone et al. is focused on a similar way, highlighting the importance of generating an ecosystem of services and benefits for users that are part of the shared service of electric vehicles. These authors propose a model by means of which the users 
can count on the possibility of renting an electric car and returning it in any of the points of the system, besides having advantages such as free parking, an interactive system to obtain information about the mobility of the city and access to areas of limited traffic (Mingrone, Pignataro, \& Roscia, 2015). Himmel et al. also present an urban mobility system focused on the intermodality of means of transport to offer a complete experience to its users. This system is called Mobility Broker and has a configuration of an app that helps manage travel, as well as the planning of journeys and the reservation of electric vehicles and electric bicycles. In conclusion, it shows how the user experience is very important in changing urban mobility according to its direct relationship with the system and its possibility for personalised adjustment according to needs (Himmel et al., 2016). Andaloro et al. highlight the need to propose a cargo transport system that is responsible both for the use of electric vehicles for deliveries to the interior of cities, as well as for the clean generation of energy (OR generation of clean energy). The construction of the vehicle presented had a special selection of elements so that its investment in technology was low cost (Andaloro et al., 2015)where $68 \%$ of the EU population lives using $70 \%$ of the energy, an integrated and sustainable urban approach is needed. In order to meet the increasingly complex challenges of urban areas new, efficient, and user-friendly technologies and services, in particular in areas of energy, transport, and ICT are required. In the transport sector electric urban mobility and synergy between different transport systems (ITS. Finally, Dimitrakopoulos emphasizes the construction of 5G networks that allow the incursion of autonomous vehicles that provide safety and comfort to users. His proposal works through Vehicell, an intelligent interface that manages the information of the city and chooses the best options for efficient mobility (Dimitrakopoulos, 2017).

\subsubsection{Co-operative platforms for smart mobility}

This line considers that the participation of citizens and stakeholders (municipalities, users, and transport providers) is a key element for the success of sustainable urban mobility. For the proper functioning of transport, intelligence is required both for transport and for users. This analysis emphasises that, in the context of urban mobility, smart mobility technologies can help people access and exploit multimodal mobility options and make the most of available mobility alternatives. However, mobility technologies do not only affect mobility practices and user behaviour. They can also improve transport and mobility planning in cities. The key aspects are the exchange of data, the generation of data, the integration of different types of data and the participation of citizens in the collection of data (crowdsourcing) (Lenz \& Heinrichs, 2017).

In the emergence of systems for intelligent urban mobility, developments focused on the creation of user co-operative networks that interact from different levels. In some cases, co-operation allows sending information that is condensed by an administrator to have up-to-date information in real-time that helps in making decisions about urban mobility. Leone et al. propose a mobility system based on a co-operative network of visual sensors that communicate through a wireless network compatible with devices and elements of IoT (Internet of Things) in which images can be captured by integrated cameras to capture information about the city. The co-operative network of visual sensors is responsible for collecting and adding events related to an intelligent transport system providing advanced services to users (Leone et al., 2017).

Other cases raise participation levels whereby the user can interact with others, comment, publish, make recommendations, and develop their own projects. Severengiz et al. address the creation of a sustainable manufacturing community
(SMC) through a web platform where people can contribute and access others' contributions to develop various projects. The SMC communities' approach is characterised using ICT and applications that allow global citizenships to be configured based on the transfer of knowledge. Global thinking processes are strengthened without losing local needs. Its bases are found in the construction of open and free knowledge as essential elements of the SMC (Severengiz, Seidel, Steingrímsson, \& Seliger, 2015). Ferreira et al. contribute from the PASMO project, an open living laboratory for the development of Smart Cities and Smart Communities, open to companies, municipalities, and research institutions. The project has a strong focus on smart mobility and co-operative ITS applications, based on a set of different protocols and communication standards (Ferreira et al., 2017).

Pitt et al. focus on how an integration of the cyber-physical systems can be made with the socio-technical systems where users and consumers can become collaborators and participants in the management of these systems. They propose a system of polycentric governance from a community space that opens the possibility of citizen participation and energy consumption in such a way that self-government is established for self-management of a city's energy-related processes. Although this study focuses on energy management, it also delves into concepts of intelligent management of urban mobility (Pitt, Diaconescu, \& Bourazeri, 2017).

\subsubsection{Platforms for urban mobility}

This latest finding brings together all those urban mobility platforms that integrate smart services assuming the need for a comprehensive approach to sustainable cities. The progress of the Integrated Real-time Mobility Assistant project (IRMA) is important in this analysis. IRMA presents integrated mobility solutions for users, orientating green, shared and public transport services under a digital infrastructure (Motta, Sacco, Ma, You, \& Liu, 2015). The approaches of experimenting with the TETRis model ${ }^{2}$ in the creation of an intelligent environment for urban mobility by means of social sensors are interesting. This model provides tools for both citizens and city managers in such a way that everyone has access to information in real-time, can make alerts about situations that arise in the city while maintaining close contact between citizens and government (Citrigno, Graziano, Lupia, \& Saccà, 2014). It is worth highlighting previous solutions about urban mobility atlases that offer complete catalogues of mobility behaviours in a city to explore the changing circumstances of a city (Batty et al., 2012).

Marchetta et al. allows the articulation of an efficient urban network with information shared by its users and by institutional actors through an interactive map that provides a set of services for urban mobility (Marchetta, Natale, Pescape, Salvi, \& Santini, 2016)a new vision of urban mobility, is a reality. To implement smart mobility scenarios a deep integration among citizens, private and public transportation systems and ICT is required. With the S2-Move project we propose an architecture able to collect, update, and process real-Time and heterogeneous information from various sources (tablets, smart-phones, probe vehicles. Di Martino \& Rossi also advance with a convergent system of multimodal solutions for users that, in an efficient way, take into account the origin of the journeys, the destination and the knowledge of the users to achieve experiences focused on them and their needs (Di Martino \& Rossi, 2016). Falco et al. contributes to

2 'TETRis focuses on innovative services for Smart City/Smart Territory via the definition of technological tools and intelligent platforms which enable local organizations to acquire, represent and manage data and information gathered from sensors and devices by means of several communication systems deployed in the vest of add-value services' (Citrigno et al., 2014) (p. 1). 
this field with the concept of Infostructures proposing data networks and open codes for urban mobility in cities with public transport infrastructure difficulties and high dependence on private vehicles. This is done in such a way that the possibility of creating solutions together and proposing new dynamics within the city empowers citizens and makes them part of the construction of social welfare. The ICTs here are important because they allow a closer relationship with the user and allow them to have all the necessary information to make decisions about the means of transport and routes they can take to reach a certain destination (Falco et al., 2018). Kazhamiakin et al. integrate an element to these advances with their interest in generating changes in the behaviour of users from the integration of playful systems typical of gamification trends, sustaining how smart cities not only present an intelligent technical infrastructure, but also that its citizens need to articulate with these developments (Kazhamiakin, Marconi, Martinelli, Pistore, \& Valetto, 2016). Oskarbski \& Kaszubowski are concerned with digital tools that help with the integration of the cargo transport system that allows the generation of solutions based on traffic modelling to plan routes, monitor in real-time and forecast congestion and traffic incidents. Further possibilities include dynamic vehicle routeing with real-time information and a programming guide system and parking for cargo vehicles, and use of panels with messages on the tracks (Oskarbski \& Kaszubowski, 2016).

Finally, eCOMPASS, innovation proposed by Dibbelt et al. is focused on efficiency in mobility as well as in the reduction of emissions from vehicles, including algorithms that help define routes adjusted to real-time data and user experience (knowledge of the city and route preferences) (Dibbelt et al., 2017).

\subsection{Gaps in the literature}

- Within the studies consulted there is a difficulty in integrating indicators, ways of measuring the behaviour of mobility in cities, with citizen participation and the way in which decisions are made about the use of public space through digital technologies. This means that the investigations reported in the initial part show a design of solutions that does not manage to integrate into its analysis important social variables, such as participation and the contextualized use of means of transport.

- We did not find a representative interest in generating analyses related to the size and complexities of cities, so that the concept of compact city is not included as a way of explaining the urban system and its mobility in a holistic way that not only depends on of urban transport but of the citizen exercise of the use of public space.

- There are also no studies that are questioning urban mobility through the displacement of the labour force from various points and proposing solutions such as the massification of telework and its adaptation to urban dynamics.

- Although the recommendations of organizations such as the UN (2015) on the analysis of urban mobility are related to broadening the horizon towards various variables typical of life in the city, still most of the articles found focus on urban transport and in its modalities excluding other complementary views. In the end, the articles that open their explanation towards participation, administration and decision-making on the public, environmental pollution, among others, from the use of digital technologies, are important.

\section{CONCLUSIONS}

Based on the articles reviewed and the analysis of urban mobility, the studies undertaken by Italy-especially university centres such as the Politecnico di Milano where the convergence of ICT and the concept of sustainability in solving problems-are noteworthy. Urban mobility is a line of research that takes strength in the academic field from various disciplines.

With the presentation of the three axes of analysis discussed in this document, the main academic tendencies and developments on urban mobility were identified. In the first analysis on modelling and simulation of vehicular traffic, the rationale lies in the use of tools that allow the measurement and prediction of the vehicular behaviour of cities through different means that have evolved as important advances occur in ICT and in the methodologies for the processing of large databases. These studies show that there is a wide applicability of the data provided by mobile phone users or obtained through sensors that can provide data for urban planning purposes, tourism management and to inform citizens to reduce inefficiencies of urban systems. However, these solutions seem scattered and without an evident articulation with holistic sustainable city projects that imply the use of ICT with a long-range vision and without necessarily evidencing their positive impact on urban mobility.

In the following axes, the academic studies are addressed in the analysis of the incursion of ICT in urban mobility. It is possible to observe how the meaning of ICT permutes towards a broader understanding of social transformations typical of smart cities. So much so that discussions based on systems theory are included for the understanding of sociotechnical phenomena and to give a broader framework of analysis where urban mobility is an activity that is related to others in the city system.

In the last axes on alternatives that have been designed for the evolution of urban mobility, there is a wide field of work that deals with convergent solutions according to the specific contexts of cities and the profile of their users. This type of proposal allows us to understand how urban mobility requires heterogeneous approaches in which participation and co-operativism among citizens facilitates the generation of innovative solutions. In addition, it is an academic trend that integrates sustainable urban mobility management alternatives where ICT not only provides the means to obtain data, but also helps to generate a coherent integration between the traditional systems of cities, new digital systems, and the recognition of the user as an essential actor in the construction of sustainable solutions.

\section{Conflicts of Interest:}

The authors declare no conflict of interest.

\section{REFERENCES}

Aguiléra, A., \& Grébert, J. (2014). Passenger transport mode share in cities: Exploration of actual and future trends with a worldwide survey. International Journal of Automotive Technology and Management, 14(3-4), 203-216. https://doi.org/10.1504/IJATM.2014.065290

Alam, M., Fernandes, B., Almeida, J., Ferreira, J., \& Fonseca, J. (2017). Integration of smart parking in distributed ITS architecture. In ICOSST 2016 - 2016 International Conference on Open Source Systems and Technologies, Proceedings (pp. 84-88). https://doi.org/10.1109/ICOSST.2016.7838582

Andaloro, L., Napoli, G., Sergi, F., Micari, S., Agnello, G., $\&$ Antonucci, V. (2015). Development of a new concept electric vehicle for last mile transportations. World Electric Vehicle Journal, 7(3), 342-348.

Arena, M., Azzone, G., Colorni, A., Conte, A., Luè, A., $\&$ Nocerino, R. (2015). Service design in electric vehicle sharing: Evidence from Italy. IET Intelligent Transport Systems, 9(2), 145-155. https://doi.org/10.1049/iet-its.2013.0034 
Arimah, B. (2017). Infrastructure as a Catalyst for the Prosperity of African Cities. In Procedia Engineering (Vol. 198, pp. 245-266). https://doi.org/10.1016/j.proeng.2017.07.159

Arsenio, E., Dias, J. V., Lopes, S. A., \& Pereira, H. I. (2017). Assessing the market potential of electric bicycles and ICT for low carbon school travel: A case study in the smart city of Águeda. In Transportation Research Procedia (Vol. 26, pp. 119-130). https://doi.org/10.1016/j.trpro.2017.07.013

Battarra, R., Zucaro, F., \& Tremiterra, M. R. (2017). Smart mobility: An evaluation method to audit Italian cities. In 5th IEEE International Conference on Models and Technologies for Intelligent Transportation Systems, MT-ITS 2017 - Proceedings (pp. 421-426). https://doi.org/10.1109/MTITS.2017.8005709

Batty, M., Axhausen, K. W., Giannotti, F., Pozdnoukhov, A., Bazzani, A., Wachowicz, M., ... Portugali, Y. (2012). Smart cities of the future. European Physical Journal: Special Topics, 214(1), 481-518. https://doi.org/10.1140/epjst/e2012-01703-3

Batur, İ., \& Koç, M. (2017). Travel Demand Management (TDM) case study for social behavioral change towards sustainable urban transportation in Istanbul. Cities, 69, 20-35. https://doi.org/10.1016/j.cities.2017.05.017

Calabrese, F., Colonna, M., Lovisolo, P., Parata, D., \& Ratti, C. (2011). Real-Time Urban Monitoring Using Cell Phones: A Case Study in Rome. IEEE Transactions on Intelligent Transportation Systems, 12(1), 141-151. https://doi.org/10.1109/

TITS.2010.2074196

Camagni, R., Gibelli, M. C., \& Rigamonti, P. (2002). Urban mobility and urban form: the social and environmental costs of different patterns of urban expansion. Ecological Economics, 40(2), 199-216. https://doi.org/10.1016/S0921-8009(01)00254-3

Cárdenas-Benítez, N., Aquino-Santos, R., Magaña-Espinoza, P., Aguilar-Velazco, J., Edwards-Block, A., \& Cass, A. M. (2016). Traffic congestion detection system through connected vehicles and big data. Sensors (Switzerland), 16(5). https://doi.org/10.3390/s16050599

Citrigno, S., Graziano, S., Lupia, F., \& Saccà, D. (2014). Smart applications for smart city: A contribution to innovation. In CEUR Workshop Proceedings (Vol. 1133, pp. 365-366).

Cohen-Blankshtain, G., \& Rotem-Mindali, O. (2016). Key research themes on ICT and sustainable urban mobility. International Journal of Sustainable Transportation, 10(1), 9-17. https://doi.org/10.1080/15568318.2013.820994

Costa, P. B., Morais, G. C., \& Bertolde, A. I. (2017). Urban Mobility Indexes: A Brief Review of the Literature. Transportation Research Procedia, 25, 3645-3655. https://doi.org/10.1016/I. TRPRO.2017.05.330

D'Andrea, E., \& Marcelloni, F. (2017). Detection of traffic congestion and incidents from GPS trace analysis. Expert Systems with Applications, 73, 43-56. https://doi.org/10.1016/i. eswa.2016.12.018

Daganzo, C. F. (2007). Urban gridlock: Macroscopic modeling and mitigation approaches. Transportation Research Part B- Methodological, 41(1), 49-62. https://doi.org/10.1016/j. trb.2006.03.001

Daganzo, C. F., Gayah, V. V, \& Gonzales, E. J. (2011). Macroscopic relations of urban traffic variables: Bifurcations, multivaluedness and instability. Transportation Research Part B-Methodological, 45(1), 278-288. https://doi.org/10.1016/j.trb.2010.06.006

Daly, H. (1990). Toward some operational principles of Sustainable Development. Ecological Economics, 2, 1-6.

Di Martino, S., \& Rossi, S. (2016). An Architecture for a Mobility Recommender System in Smart Cities. In Procedia Computer Science (Vol. 58, pp. 425-430). https://doi.org/10.1016/j. procs.2016.09.066

Dibbelt, J., Kehagias, D., Pantziou, G., Gavalas, D., Konstantopoulos, C., Wagner, D., ... Zaroliagis, C. (2017). Ecoaware vehicle routing in urban environments. In Proceedings IEEE Symposium on Computers and Communications (pp. 208-213). https://doi.org/10.1109/ISCC.2017.8024531
Dimitrakopoulos, G. (2017). Sustainable mobility leveraging on 5G mobile communication infrastructures in the context of smart city operations. Evolving Systems, 8(2), 157-166. https://doi.org/10.1007/s12530-016-9166-4

Djahel, S., Doolan, R., Muntean, G.-M., \& Murphy, J. (2015). A Communications-Oriented Perspective on Traffic Management Systems for Smart Cities: Challenges and Innovative Approaches. IEEE Communications Surveys and Tutorials, 17(1), 125-151. https://doi.org/10.1109/ COMST.2014.2339817

Elhatri, C., Tahifa, M., \& Boumhidi, J. (2017). Extreme Learning Machine-Based Traffic Incidents Detection with Domain Adaptation Transfer Learning. Journal of Intelligent Systems, 26(4), 601-612. https://doi.org/10.1515/jisys-2016-0028

Falco, E., Malavolta, I., Radzimski, A., Ruberto, S., Iovino, L., \& Gallo, F. (2018). Smart City L'Aquila: An Application of the "Infostructure" Approach to Public Urban Mobility in a PostDisaster Context. Journal of Urban Technology, 25(1), 99-121. https://doi.org/10.1080/10630732.2017.1362901

Ferreira, J., Fonseca, J., Gomes, D., Barraca, J., Fernandes, B., Rufino, J., ... Aguiar, R. (2017). PASMO: An open living lab for cooperative ITS and smart regions. In 2017 International Smart Cities Conference, ISC2 2017. https://doi.org/10.1109/ ISC2.2017.8090866

Fistola, R., Raimondo, M., \& Rocca, R. A. L. (2017). The smart city and mobility: The functional polarization of urban flow. In 5th IEEE International Conference on Models and Technologies for Intelligent Transportation Systems, MT-ITS 2017 - Proceedings (pp. 532-537). https://doi.org/10.1109/ MTITS.2017.8005730

Geroliminis, N., \& Daganzo, C. F. (2008). Existence of urban-scale macroscopic fundamental diagrams: Some experimental findings. Transportation Research Part B-Methodological, 42(9), 759-770. https://doi.org/10.1016/j.trb.2008.02.002

Himmel, S., Zaunbrecher, B. S., Ziefle, M., \& Beutel, M. C. (2016). Chances for urban electromobility: Field test of intermodal travel system and effect on usage intention. Lecture Notes in Computer Science (including subseries Lecture Notes in Artificial Intelligence and Lecture Notes in Bioinformatics) (Vol. 9747). https://doi.org/10.1007/978-3-319-40355-7_45

Jensen, O. B. (2013). Staging mobilities. Staging Mobilities (1st Editio). London. https://doi.org/10.4324/9780203070062

Kahlen, M., Lee, T. Y., Ketter, W., \& Gupta, A. (2018). Optimal Prepositioning and Fleet Sizing to Maximize Profits for OneWay Transportation Companies. In ICIS 2017: Transforming Society with Digital Innovation.

Kamargianni, M., Li, W., Matyas, M., \& Schäfer, A. (2016). A Critical Review of New Mobility Services for Urban Transport. Transportation Research Procedia, 14, 3294-3303. https://doi.org/10.1016/J.TRPRO.2016.05.277

Kazhamiakin, R., Marconi, A., Martinelli, A., Pistore, M., $\&$ Valetto, G. (2016). A gamification framework for the longterm engagement of smart citizens. In IEEE 2nd International Smart Cities Conference: Improving the Citizens Quality of Life, ISC2 2016 - Proceedings. https://doi.org/10.1109/ ISC2.2016.07580746

Kourtit, K., Nijkamp, P., Franklin, R., \& Rodríguez-Pose, A. (2014). A blueprint for strategic urban research: The urban piazza. Town Planning Review, 85(1), 97-126. https://doi.org/10.3828/ tpr.2014.7

Kozievitch, N. P., Gomes, L. C., Gadda, T. M. C., Fonseca, K. V. O., \& Akbar, M. (2016). Analyzing the acoustic urban environment: A geofencing-centered approach in the Curitiba metropolitan region, Brazil. In Smartgreens 2016 - Proceedings of the 5th International Conference on Smart Cities and Green ICT Systems (pp. 78-85).

Lenz, B., \& Heinrichs, D. (2017). What Can We Learn from Smart Urban Mobility Technologies? IEEE Pervasive Computing, 16(2), 84-86. https://doi.org/10.1109/MPRV.2017.27 
Leone, G. R., Moroni, D., Pieri, G., Petracca, M., Salvetti, O., Azzarà, A., \& Marino, F. (2017). An intelligent cooperative visual sensor network for urban mobility. Sensors (Switzerland), 17(11). https://doi.org/10.3390/s17112588

Li, F. Z., Fisher, K. J., Brownson, R. C., \& Bosworth, M. (2005). Multilevel modelling of built environment characteristics related to neighbourhood walking activity in older adults. Journal of Epidemiology and Community Health, 59(7), 558-564. https://doi.org/10.1136/jech.2004.028399

Li, N., Chan, D., Hsu, K., Fu, Z., \& Mao, Q. (2017). ICT-Enabled Cross-Cultural Education in Sustainable Urbanization. In Congress on Computing in Civil Engineering, Proceedings (Vol. 2017-June, pp. 43-50).

Lopez-Carreiro, I., \& Monzon, A. (2018). Evaluating sustainability and innovation of mobility patterns in Spanish cities. Analysis by size and urban typology. Sustainable Cities and Society, 38, 684-696. https://doi.org/10.1016/j. scs.2018.01.029

López Bernal, O. (2004). La sustentabilidad urbana. Revista Bitácora Urbano Territorial, 1(8), 8-14. Retrieved from http://www.redalyc.org/articulo.oa?id=74800801

Marchetta, P., Natale, E., Pescape, A., Salvi, A., \& Santini, S. (2016). A map-based platform for smart mobility services. In Proceedings - IEEE Symposium on Computers and Communications (Vol. 2016-Febru, pp. 19-24). https://doi.org/10.1109/ISCC.2015.7405448

Marletto, G. (2014). Car and the city: Socio-technical transition pathways to 2030. TECHNOLOGICAL FORECASTING AND SOCIAL CHANGE, 87, 164-178. https://doi.org/10.1016/j. techfore.2013.12.013

Mataix, C. (2010). Movilidad Urbana Sostenible: un reto energético y ambiental. Madrid: Obra Social Caja Madrid.

Mingrone, L., Pignataro, G., \& Roscia, M. (2015). Smart urban electric transport system: An innovative real model. In 2015 International Conference on Renewable Energy Research and Applications, ICRERA 2015 (pp. 1457-1462). https://doi.org/10.1109/ICRERA.2015.7418649

Motta, G., Sacco, D., Ma, T., You, L., \& Liu, K. (2015). Personal mobility service system in urban areas: The IRMA project. In Proceedings - 9th IEEE International Symposium on ServiceOriented System Engineering, IEEE SOSE 2015 (Vol. 30, pp. 88-97). https://doi.org/10.1109/SOSE.2015.15

Oskarbski, J., \& Kaszubowski, D. (2016). Potential for ITS/ICT Solutions in Urban Freight Management. In Transportation Research Procedia (Vol. 16, pp. 433-448). https://doi.org/10.1016/j.trpro.2016.11.041

Passalacqua, A. (2014). Reluctant capitals: Transport mobility and tramways in London and Paris 1830-1950. Town Planning Review, 85(2), 203-216. https://doi.org/10.3828/tpr.2014.13

Pitt, J., Diaconescu, A., \& Bourazeri, A. (2017). Democratisation of the SmartGrid and the active participation of prosumers. In IEEE International Symposium on Industrial Electronics (pp. 1707-1714). https://doi.org/10.1109/ISIE.2017.8001505

Pronello, C., Duboz, A., \& Rappazzo, V. (2017). Towards smarter urban mobility: Willingness to pay for an advanced traveller information system in Lyon. Sustainability (Switzerland), 9(10). https://doi.org/10.3390/su9101690

Rakkesh, S. T., Weerasinghe, A. R., \& Ranasinghe, R. A. C. (2016). Traffic light optimization solutions using multimodal, distributed and adaptive approaches. In 15th International Conference on Advances in ICT for Emerging Regions, ICTer 2015 - Conference Proceedings (pp. 220-225). https://doi.org/10.1109/ICTER.2015.7377692

Rehm, S.-V., Faber, A., \& Goel, L. (2018). Visualizing Platform Hubs of Smart City Mobility Business Ecosystems. In ICIS 2017: Transforming Society with Digital Innovation.

Schwanen, T. (2015). Beyond instrument: Smartphone app and sustainable mobility. European Journal of Transport and Infrastructure Research, 15(4), 675-690.
Serna, A., Gerrikagoitia, J. K., Bernabé, U., \& Ruiz, T. (2017). Sustainability analysis on Urban Mobility based on Social Media content. In Transportation Research Procedia (Vol. 24). https://doi.org/10.1016/j.trpro.2017.05.059

Severengiz, M., Seidel, J., Steingrímsson, J. G., \& Seliger, G. (2015). Enhancing technological innovation with the implementation of a sustainable manufacturing community. In Procedia CIRP (Vol. 26, pp. 52-57). https://doi.org/10.1016/i. procir.2014.07.177

Shields, A., Doody, P., \& Scully, T. (2017). Application of multiple change point detection methods to large urban telecommunication networks. In 2017 28th Irish Signals and Systems Conference, ISSC 2017. https://doi.org/10.1109/ ISSC. 2017.7983608

Snellen, D., \& de Hollander, G. (2017). ICT'S change transport and mobility: mind the policy gap! Transportation Research Procedia, 26(Emerging technologies and models for transport and mobility), 3-12. https://doi.org/10.1016/i. trpro.2017.07.003

Steenbruggen, J., Tranos, E., \& Nijkamp, P. (2015). Data from mobile phone operators: A tool for smarter cities? Telecommunications Policy, 39(3-4), 335-346. https://doi.org/10.1016/i.telpol.2014.04.001

Tafidis, P., Macedo, E., Coelho, M. C., Niculescu, M. C., Voicu, A., Barbu, C., ... Bandeira, J. (2017). Exploring the impact of ICT on urban mobility in heterogenic regions. In Transportation Research Procedia (Vol. 27, pp. 309-316). https://doi.org/10.1016/j. trpro.2017.12.030

Tyfield, D., \& Zuev, D. (2018). Stasis, dynamism and emergence of the e-mobility system in China: A power relational perspective. Technological Forecasting and Social Change, 126, 259-270. https://doi.org/10.1016/j.techfore.2017.09.006

United Nations. (2015). Sustainable Development Goals. Retrieved 12 March 2017, from http://www.un.org/ sustainabledevelopment/sustainable-development-goals/ United Nations. (2017). World Population Prospects: The 2017 Revision, Key Findings and Advance Tables. (No. ESA/P/ WP/248). Retrieved from https://esa.un.org/unpd/wpp/ Publications/Files/WPP2017 KeyFindings.pdf

Vidovic, K., Mandzuka, S., \& Brcic, D. (2017). Estimation of urban mobility using public mobile network. In Proceedings Elmar International Symposium Electronics in Marine (Vol. 2017-Septe, pp. 21-24). https://doi.org/10.23919/ELMAR.2017.8124426

Zhang, X., \& Li, H. (2018). Urban resilience and urban sustainability: What we know and what do not know? Cities, 72, 141-148. https://doi.org/10.1016/j.cities.2017.08.009

Zheng, Y., Rajasegarar, S., \& Leckie, C. (2015). Parking availability prediction for sensor-enabled car parks in smart cities. In 2015 IEEE 10th International Conference on Intelligent Sensors, Sensor Networks and Information Processing, ISSNIP 2015. https://doi.org/10.1109/ISSNIP.2015.7106902 